\title{
The Analysis of the Product Design Under the Influence of Modernism Design Style*
}

\author{
Xiaochen Geng \\ Xiamen Academy of Arts and Design \\ Fuzhou University \\ Fuzhou, China \\ Postdoctoral Research Station \\ Nanjing Normal University \\ Nanjing, China
}

\author{
Shaopeng $\mathrm{Wu}$ \\ Xiamen Academy of Arts and Design \\ Fuzhou University \\ Fuzhou, China
}

\author{
Zhiqiang Lin \\ Xiamen Academy of Arts and Design \\ Fuzhou University \\ Fuzhou, China
}

\begin{abstract}
In this paper, the influence of modernism design style on product design is described. We reviewed the appearance of the modernism design style and analyzed the reason that product design was still popular even influenced by the modernism design style. Then, on this basis, we proposed the opinion that the modernism would still occupy a place in the future of product design. Finally, we looked into the future of product design under the influence of modernism design style.
\end{abstract}

Keywords-modernism product design; science and technology development

\section{INTRODUCTION}

Product design is a creative activity of human beings. It can be said that from the time when mankind made the first polished stone tool, product design exists in the human creation activity, and it is always accompanied by the occurrence and development of human creation activity. With certain creative activities gaining independence from direct loss of purely utilitarian purposes, the spiritual content of these activities or products has been intensified, mental activities have gradually separated from physical activities, and the original theoretical ideas have been produced. These humans the crystallization of spiritual culture guides human creation activities from its inception and composes the human creation epic. Various theories and styles of product design are emerging in the process of design. This article analyzes and discusses the influence of modernist design

*In 2014, China National Social Science Foundation Art Project, Research of Chinese Pewter craft culture and its artistic active state inheritance, project number: 2014CG134, initial results;

In 2015, China Postdoctoral Science Foundation, Research about the Radiation and Inheritance of Chinese Pewter art in Southeast Asia, number: 2015M570465, initial results;

In 2015, high-level "211" Engineering University Project, Fuzhou University Art Theory discipline support program, initial results; style on product design.

\section{GENERATION OF MODERNIST DESIGN STYLE}

The modernist design style was born in the early days of the industrial society in the 1920s. It originated in the United Kingdom and developed in Europe, the United States, and Japan. It reached its peak in the 1950s and 1960s. The aesthetic concept of modernist design style is mainly advocating simple, functional and rational forms. This idea has been affecting many fields including industrial design, graphic design, and environmental design since the beginning of architectural design.

The modernist design that developed from the 1920s has distinct formal features. It advocates the use of simple geometric shapes in form; and opposes the use of decorations in design. Its degree of objection to ornamentation is even reflected in the design's color scheme. We look at the design of modernism in terms of black and white neutral colors. At the same time, modernism design attaches great importance to space considerations in the specific design process, emphasizing the rational arrangement of space from an overall perspective. These formal features of modernism are closely related to its original development in the area of architectural design. Geometry provides great possibilities for the reorganization of the architectural design space. For example, the six-sided building has achieved a complete sixsided form of architecture. The use of neutral colors is also in line with the ideology and technical requirements of modern architecture.

Modernism has a profound ideological foundation from the very beginning. It was developed from architectural design, initially to oppose the elitism that had long been used

Wang Shou Zhi. History of modern design [M] .Beijing: China Youth Press, 2003.109 
to design a handful of elites, and it hoped to use design to change the hardships of the poor. Therefore, corresponding to its ideological foundation, economic issues have become an important consideration in modern architectural design, trying to minimize the cost and expense of design objects in the design process, so as to achieve economic and applicable purposes. Based on this, a large number of industrial building materials such as cement, glass, steel, and hollow bricks have been used in the field of architectural design; a large number of standardized methods have also been adopted to mass-produce building parts for assembly, and the assembly method has also become a basic construction method for modern buildings. The cost of such construction has been greatly reduced, and cheap buildings that reduce production costs have become affordable to the general public. These methods have become an important means of modernist ideology services.

At the same time, the design was first created for the practical needs of humans, and thus the function is the center and purpose of the design. One of the important features of modernism is to pay attention to the scientific nature of design, and to emphasize the practical role that design plays in people's lives. Whether it is scientific, convenient, and efficient has also become a prominent feature of modernist design.

\section{THE EMBODIMENT OF MODERNISM DESIGN STYLE IN PRODUCT DESIGN}

Although modernism first started from the architectural field, it subsequently influenced other design fields. Industrial product design was one of the most important areas affected.

The idea of serving the masses is prominent in the design of cars in many product designs. At the beginning of the invention, the car was designed to serve the public at the same time as the original architectural design. The car was designed for a small number of elites. In 1908, the Ford Motor Company withdrew from the first type of T-type car for public service through improvements in scientific management, assembly line production methods, and standard parts. This car was only 460 U.S. dollars by 1920 , and it has become a name. In fact, the public can afford cars. In addition, many European cars have also begun to develop mass demand cars, various models of German Volkswagen AG, and the snow-fumes of the French company Citroën. At this point, practical, inexpensive, and convenient small-sized Volkswagens have become the mainstream of automotive design. The purpose of any product's invention is to satisfy the practical purposes of the people. The product design of modernism focuses on sincere and rational thinking in design. Its core is functionalism, and anti-decorative functionalism makes it possible to completely produce modern products. The combination of modern production methods, mass production of machinery makes the simple and useful products flow into millions of households, and finally realizes the design idea of serving the public.

After entering the 21st century, the development of information technology undoubtedly brought us a new beginning. The formal features of modernist design are reflected in Apple's products. Its formal characteristics are first embodied in the product's shape, ipad, iphone and other products are simple geometric shapes, simple and beautiful; Second, the color also uses the classic design of modernism black, white, gray as the appearance of the product At the same time, Apple also pays attention to designing from an overall perspective, and we have an overview of the design style of its products, whether it is the appearance of its products or the interface design of the operating system. It can be said that the simple modernism design style of Apple products has become a "global tool", and it completely leads the design trend.

The world-famous home furnishing product IKEA is the representative of Swedish home furnishing. It emphasizes people-oriented, simple and practical and innovative. IKEA's product tenet and business philosophy are to create a beautiful and comfortable life for the public, providing a variety of concise, beautiful, practical, and popular All the home products that can be enjoyed have been praised by people all over the world. IKEA furniture products are basically modular combinations that can be assembled and disassembled and are relatively independent. Through innovative design and constant development, the products cover almost all the home furnishings. The modularization of product design can not only be produced in different countries, but also some modules can be used in different furniture combinations. This facilitates the production of large-scale machines and makes it possible to produce on a global scale. Modular design method makes IKEA products can be transported by flat packaging. Flat packaging reduces the logistics cost of the product and the space cost of storage is reduced, and finally achieve new concepts of low price and new style, leading the design of consumer value. The simplicity, practicality, and naturalness of IKEA's product design styles are clearly adhering to modernist design techniques, but there is no lack of quiet and natural Scandinavian style. It is a perfect combination of modernist design with traditional craftsmanship and modern technology.

\section{THE PRACTICAL SIGNIFICANCE OF MODERNIST Design STYLE PROducts In CHINA}

Modernism design can be understood as "functionalism" design. It emphasizes the function of design, takes function as the starting point of design, and pays attention to the scientific nature of design, convenience, comfort and efficiency in use, and highlights the economy of design. Li Yu stated in his "Everything like it" that "the mortals make things, so that everyone can prepare, and every family is available." In this regard, modernist design is of practical significance because it can meet people are certain needs. Can adjust and control the material exchange between man and nature.

From the perspective of China's reality, the most basic principles of modernist design are still quite popular. Until the late 1980's, modernist design showed its charm in China. At that time, European and American modernism designs had already emerged from the international style. The various styles of personalization, post-modernism are in the 
forefront of Europe and the United States, and in China, practical and not unsophisticated modernist style still prevails, and there has been no decline in more than two decades.

From the arts and crafts of the 1950s and 1960s to the current art design, the products designed by modernism are all attached to daily life. It can be said that modernist design is rooted in life and serves life, and acts on various aspects of life. Although China has a vast area and abundant resources, the pace of economic development and urban construction has been changing with each passing day, and various capital cities such as provincial capitals and the eastern coast have become more developed. However, because of the large population and historical reasons, the towns in some remote areas are still relatively backward. These areas of our country are still in the development stage. At this stage, we still need a large amount of cheap goods, emphasizing functional daily products to meet the needs of the broad masses of people, while modernism design style products are weakened and decorated, emphasizing functions, and being easy to produce and convenient. The features used are in line with the fact that the standardization and the assembly line greatly reduce the product cost so that ordinary people can enjoy their products.

At present, in China's large cities, because of the rapid development of material production and economic development, the overall functionality of the city cannot keep up with the speed of development. The continuous influx of population from cities to cities has led to a decline in urban basic functions. The plethora of cities make people living in metropolitan areas feel mentally exhausted. They will see people holding simple and portable modernist mobile phones or electronic products when driving roads, when they are riding on the subway or by bus, and when they are queuing for dinner. Used to kill time, but also pleasing the spirit to squeeze their own pressure. Simple and fashionable modernist products began to accompany people to urban life and gradually became the spiritual companions of urban people. The products of modernist design style undoubtedly play the role of balanced adjustment in the current urban life. The simple and practical features of modernist design style products reflect the needs of people at the very beginning and even today. What is worth mentioning here is that the products that prevail in modernist design styles in China still present two extremes? In a remote area where material needs have not yet developed to a certain height, there is still a considerable demand for modernist design style products, and the other is the urban spiritual needs that are already in line with the world. This group of people is seeking new challenges. In addition, hardware such as product design of modernist design styles should also be developed in depth, and diversified interface programs should be designed to meet the new requirements of various types of people and the development of the times. The development of the current design has entered an era of pluralistic paradigm communion. Under such a diversified background, the design community has proposed various new product design styles and concepts. In fact, these ideas are constantly changing in the development of the times.

\section{CONCLUSION}

The modernism design clearly describes its development In the information times, new technologies have brought great changes in the world economy. The product design with modernism type is as attractive as it was at the beginning of the last century, and Apple products are a good representative example. The standardization and systematicness emphasized in the product design with modernism style is still an extremely useful design method even during the period of the global economic integration. The modernism design always maintains a balance among reason, order, form and function etc. The standardized and systematic product design could provide convenience for people from different countries and different nationalities.

The world is universally connected and continuous developing. We cannot ignore the history no matter material or spiritual civilization. Instead, we should learn design experience from history and culture combining the needs of the times and the accumulation of the long history and culture. According to the laws of human development, the product design in the future will be on the basis of modernism definitely, and learn from various cultures using technology. Then a new form of product design in the future will be developed.

\section{REFERENCES}

[1] Li Yu. Xian Qing Sent [M].Chongqing: Chongqing Publishing Group in 2006.

[2] Zhuge Kai. College of Art and Design. Ten tell [M].Shandong: Pictorial Publishing House, 2006.

[3] Guo Lianfu, Mao Yanheng edited. "China Design Theory Digests" [M]. Jiangsu: Phoenix Publishing Media Group, 2008.

[4] Han Fengyuan Industrial Road of Industrial Design [J]. Packaging engineering, 2008, 24 (3): 169-171.

[5] Ming Cao Zhao Zhuan Wang Zuo New Theory [M]. Beijing: China Bookstore Publishing House, 1987.

[6] Hua Mei. A History of Modern Design [M]. Tianjin People's publishing house, 2006.

[7] Zhang Jing. "A Brief History of Design" [M]. Chongqing: Chongqing University press, 2004.

[8] Wang Shouzhi. History of Modern Design [M] .Beijing: China Youth Press, 2003. 